\title{
Ambient seismic noise tomography of Australian continent
}

\author{
Erdinc Saygin *, Brian L.N. Kennett \\ Research School of Earth Sciences, The Australian National University, Canberra ACT 200, Australia
}

\section{A R T I C L E I N F O}

\section{Article history:}

Received 15 April 2008

Received in revised form 16 November 2008

Accepted 18 November 2008

Available online 28 November 2008

\section{Keywords:}

Seismic tomography

Ambient noise correlations

Australian crust

Lithosphere

\begin{abstract}
A B S T R A C T
Imaging using information derived from the cross-correlation of the ambient seismic wavefield at different stations has recently become an important tool in seismology. We here present a continent wide study of the Australian crust based on the exploitation of continuous data from extensive portable broad-band deployments across Australia and the permanent stations. Permanent stations play a valuable role in linking the information from different portable deployments. Over 2000 Rayleigh wave components of the Green's functions are extracted from the inter-station cross-correlations and provide a reasonably uniform sampling of the continent. Rayleigh wave group velocities are extracted for the period range from $5 \mathrm{~s}$ to $12.5 \mathrm{~s}$. The group dispersion from the various paths are inverted to produce group wavespeed maps based on a $2^{\circ} \times 2^{\circ}$ grid using a nonlinear-iterative 2-D tomographic scheme with updating of propagation paths using the fast marching method. The group wavespeed maps display prominent features with lowered wavespeeds. For the shortest periods these features are mostly associated with the regions of thick sedimentary sequences, such as the Amadeus and Officer basins in central Australia. At the longer periods reduced wavespeeds are most likely due to elevated temperatures and link well to estimates of crustal heat flow. The major cratonic blocks show faster group wavespeeds, and the Archaean cratons of Western Australia are particularly fast with some indication of internal structure linked to terrane boundaries. The transition from the Precambrian core of the continent, in the centre and west, to the Phanerozoic fold belts in the east is not marked by any single well-defined anomaly in the crust, even though distinctive contrasts have been mapped in the mantle lithosphere from surface wave tomography.
\end{abstract}

(c) 2008 Elsevier B.V. All rights reserved.

\section{Introduction}

The Australian continent is comprised of a number of different tectonic blocks with Archaean and Proterozoic blocks in the western and central parts and relatively younger (Phanerozoic) units in the east. The Archaean Cratons are some of the Earth's oldest regions and carry information from the very early geological history of the Earth when the supercontinents were present and tectonic processes were possibly different than today (Betts et al., 2002).The separation of Australia and Antarctica, once joined as a part of the supercontinent Gondwana, began around 160 Ma along the southern margin of the Australian continent and the separation was complete by around $95 \mathrm{Ma} \pm 5 \mathrm{Ma}$.

Another important feature of the continental structure is the geological contrast between the Precambrian units in the west and centre to the Phanerozoic units in the east (Fig. 1a). The boundary between the Precambrian and the Phanerozoic is termed the Tasman Line but there is generally limited outcrop, and so various definitions have been proposed based on indirect geophysical evidence such as magnetic and gravity lineations (Direen and Crawford, 2003).

\footnotetext{
* Corresponding author. Present address: Geoscience Australia, ACT 2609, Canberra Australia.

E-mail address: erdinc.saygin@ga.gov.au (E. Saygin).
}

Early seismic investigations of the structure of Australian Continent used explosion data (Cleary, 1967) and earthquake data from short period instruments, e.g., Thomas (1969). These studies were able to provide some evidence of a contrast in the structure beneath the Precambrian west and central Australia and the younger provinces of east Australia. With the introduction of broad-band instrumentation, a number of temporary seismic experiments have been carried out in Australia to provide more detailed images of structure. An early result was the definition of strong contrasts in shear wavespeed between eastern Australia and the old shield regions (Zielhuis and van der Hilst, 1996).

The nature of crustal structure has been surveyed by Clitheroe et al. (2000) based on receiver functions analysis. This work also included a characterisation of the Moho discontinuity as either thin, broad or intermediate. Collins et al. (2003) summarised crustal thickness measurements, including those derived from early active source seismic refraction and reflection experiments conducted across Australia. In general, both classes of studies find a sharp Moho discontinuity beneath the oldest Archaean regions and thicker crust and a less distinct, or broader Moho beneath younger regions such as south-east Australia. More detailed studies in the west using receiver function analysis (Reading et al., 2003; Reading and Kennett, 2003) have enabled variations in crustal $S$ wavespeed within the Archaean cratons of Western Australia to be examined at the scale of major 

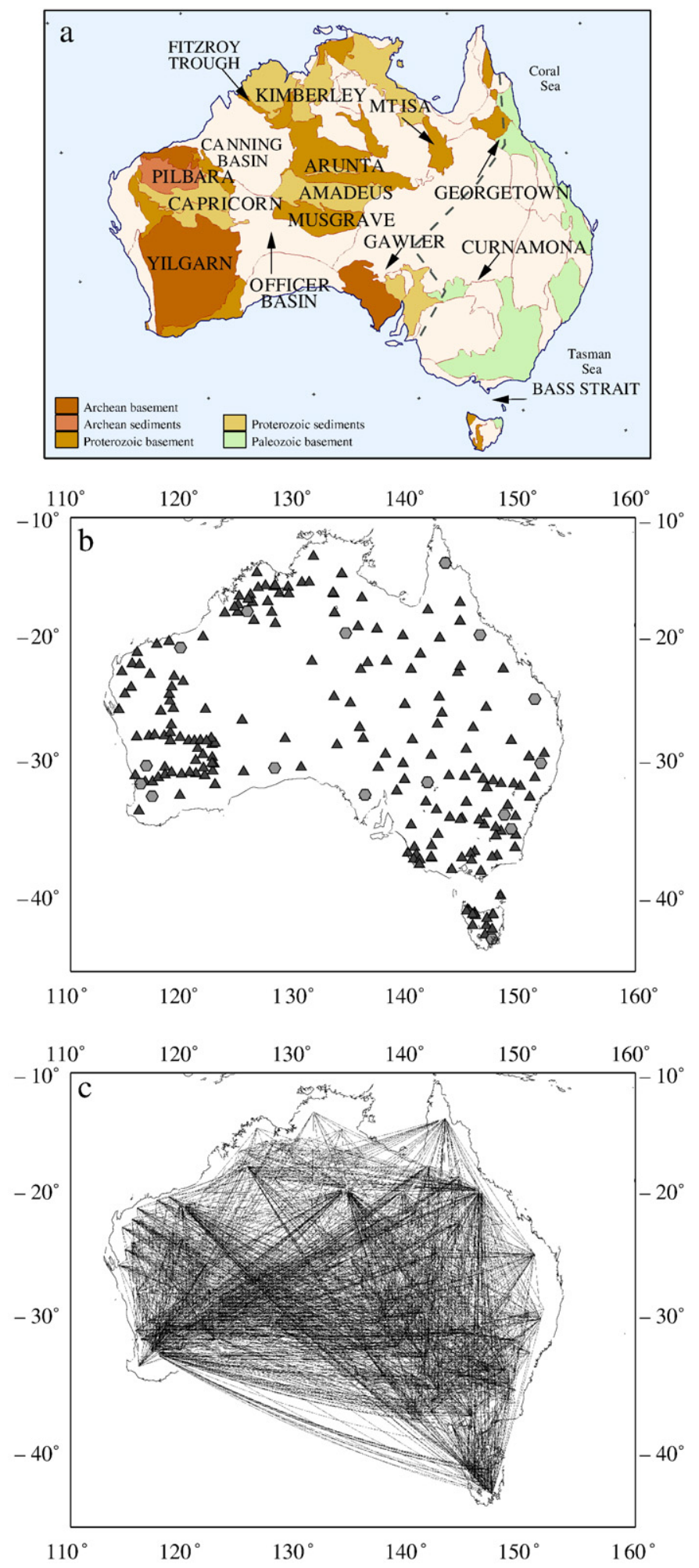

Fig. 1. a) Tectonic blocks of Australia. b) Distribution of stations used in this study. Triangles denote the temporary broad-band stations and hexagons show the permanent broad-band stations. c) Great circle paths for the Green's functions used in this study.

terrane groups. The most recent work (Reading et al., 2007) has led to insights into the formation of ancient lithosphere.

Surface wave tomography has been extensively used to examine the lithospheric mantle. The study of Simons et al. (1999) showed that the Tasman Line marking the edge of the Proterozoic shield does not have a simple relationship with the contrasts in wavespeed structure in the mantle. Further work continued to improve upon the resolution and methods employed in previous studies and is summarised by Kennett (2003). The review by Debayle and Kennett (2003) describes the extraction of information on anisotropy from surface wave observations in Australia. With the increasing coverage from the datasets as a suite of portable instrument deployments covered the continent, new techniques have been employed in surface wave based imaging. Yoshizawa and Kennett (2004) introduced a 3-stage approach for the inversion that allows the inclusion of finite frequency effects and Fishwick et al. (2005), Fishwick and Reading (2008) made use of multiple starting models to provide improved constraints on the reliability of the shear wavespeed results.

The present study focuses on the structure in the crust across the Australian continent using information derived from the correlation of ambient noise between different pairs of portable and permanent seismic stations. We exploit estimates of the Rayleigh wave component of the interstation Green's functions as the main probe for imaging the structure of the Australian crust. All of the available broad-band data recorded in the period from 1992 through 2006 was analysed to produce Green's function results from which Rayleigh wave group velocity estimates were derived. Tomographic inversion, with full propagation path updates, are used to construct 2-D images for group wavespeed appropriate to upper and middle crustal depths (5-20 km). Our results reveal a complex seismic velocity structure through the crust that had not been previously studied at the continental scale because of the limited number of local earthquakes and the paucity of permanent seismic stations.

\section{Data}

Only a limited number of high-quality permanent seismic stations span the Australian continent and so temporary experiments using portable broad-band equipment have been a major source of information on the structure of the Australian continent. The Research School of Earth Sciences, The Australian National University has conducted an extensive campaign of portable experiments since 1992, covering most of the continent with deployments of 5 months or more, many in areas with difficult environmental conditions. In the earlier experiments typically 10 stations were deployed at a time, but since 1999 about 20 stations have been used in each deployment. The distribution of the portable stations and available permanent stations is displayed in Fig. 1b. The gaps in western Australia reflect desert areas with limited access.

This study combines the broad-band data from the various portable instrument deployments. The ambient noise cross-correlation technique relies on having simultaneous recordings of the noise field at two separate seismic stations so that the Green's function between them can be extracted. Because the different deployments of portable instruments occurred at different times, we are not able to exploit all of the possible paths that might be envisaged from Fig. 1b. However, we are able to exploit permanent stations from the IRIS, GEOSCOPE, and Geoscience Australia networks to act as tie points between different deployments, since the majority of these stations have data availability extending over a period during which several portable deployments were made. All of the available vertical component broad-band data from the portable and permanent stations were used in the construction of Green's function. The shortest duration employed was 15 days, and in some cases it was possible to exploit several years of data. In all 2299 individual crosscorrelation stacks were constructed for the interstation Green's functions. The set of interstation paths provides a quasi-uniform coverage within the continent (Fig. 1c). The margins of the continent are less well sampled, and there is slightly better sampling in the south of the continent compared with the north, which reverses the familiar pattern for the exploitation of data from the regional earthquakes around Australia. 


\section{Ambient noise cross-correlations}

The idea of extracting information from a system by using random signals has its roots in electrical engineering and the fluctuationdissipation theorem of quantum physics. Lee (1960) showed that it is possible to estimate the response of a linear system by crosscorrelating the input and the output signals, when the system is excited with white noise. In geophysical work Claerbout (1968) demonstrated that the autocorrelation of the transmission response of the Earth corresponds to the superposition of the reflection response and its acausal counterpart. This approach was then applied in helioseismology to estimate the impulse response for the Sun by Duvall et al. (1993). Weaver and Lobkis (2001) used thermally induced random waves measured at two different points on a granite block, and then cross-correlated to find the elastic impulse response (Green's function) between these points. Following this work, Shapiro and Campillo (2004) adapted this idea to seismic waves and were able construct the Rayleigh wave component of the Green's function between two broad-band stations by cross-correlating the ambient seismic noise recorded at the two stations. Sabra et al. (2005) and Shapiro et al. (2005) conducted tomographic imaging of the Californian region by exploiting the dispersive properties of the Green's functions extracted from ambient-noise correlations. Since these pioneering studies the ambient-noise technique has been applied to several regions across the globe, e.g., Southern Korea (Kang and Shin, 2006), the Iberian peninsula (Villaseñor et al., 2007), the south-eastern part of the Tibetan plateau (Yao et al., 2006), Iceland (Gudmundsson et al., 2007) and the western part of the USA (Moschetti et al., 2007; Lin et al., 2008).
The present study extends the approach to cover most of the Australian continent. We use continuous broad-band data from the vertical components of over 120 temporary and permanent seismic stations operated across Australia in the period between 1992 and 2006.

The cross-correlation technique can be summarised as follows. For two stations A, B the cross-correlation integral can be written as,

$G\left(x_{\mathrm{A}}, x_{\mathrm{B}}, t\right)=\int_{-\infty}^{\infty} v\left(x_{\mathrm{A}}, \tau\right) v_{2}\left(x_{\mathrm{B}}, t+\tau\right) d \tau$,

where $v\left(x_{\mathrm{A}}, t\right)$ and $v\left(x_{\mathrm{B}}, t\right)$ represent the continuously recorded seismic velocity field at the stations A and B. Snieder (2004) showed that the result of the cross-correlation operation (1) is the time derivative of the sum of the Green's function between the two stations and its time reversed image. Thus a frequency dependent amplitude correction has to be applied to (1) to construct the true Green's function. Differentiation in time also creates a phase shift between the result of the crosscorrelation and the true Green's function. Since we only measure group wavespeed from the envelope of the estimated Green's function, this phase discrepancy is ignored and (1) is used in the actual calculations. Our data processing methodology is very similar to that of Bensen et al. (2007) but we have not introduced any modifications to the spectrum by, e.g., one-bit normalisation, spectral whitening or bandpass filtering.

To extract Green's function from the vertical component of the ground-velocity records, we have used the following scheme:

- Prepare daily SAC files for each of the stations.

- Remove the spurious records due to instrumental problems.

- Divide each of the full day records into $4 \mathrm{~h}$ segments, and then compute the cross-correlations for the corresponding station pairs with a 1 h overlap.

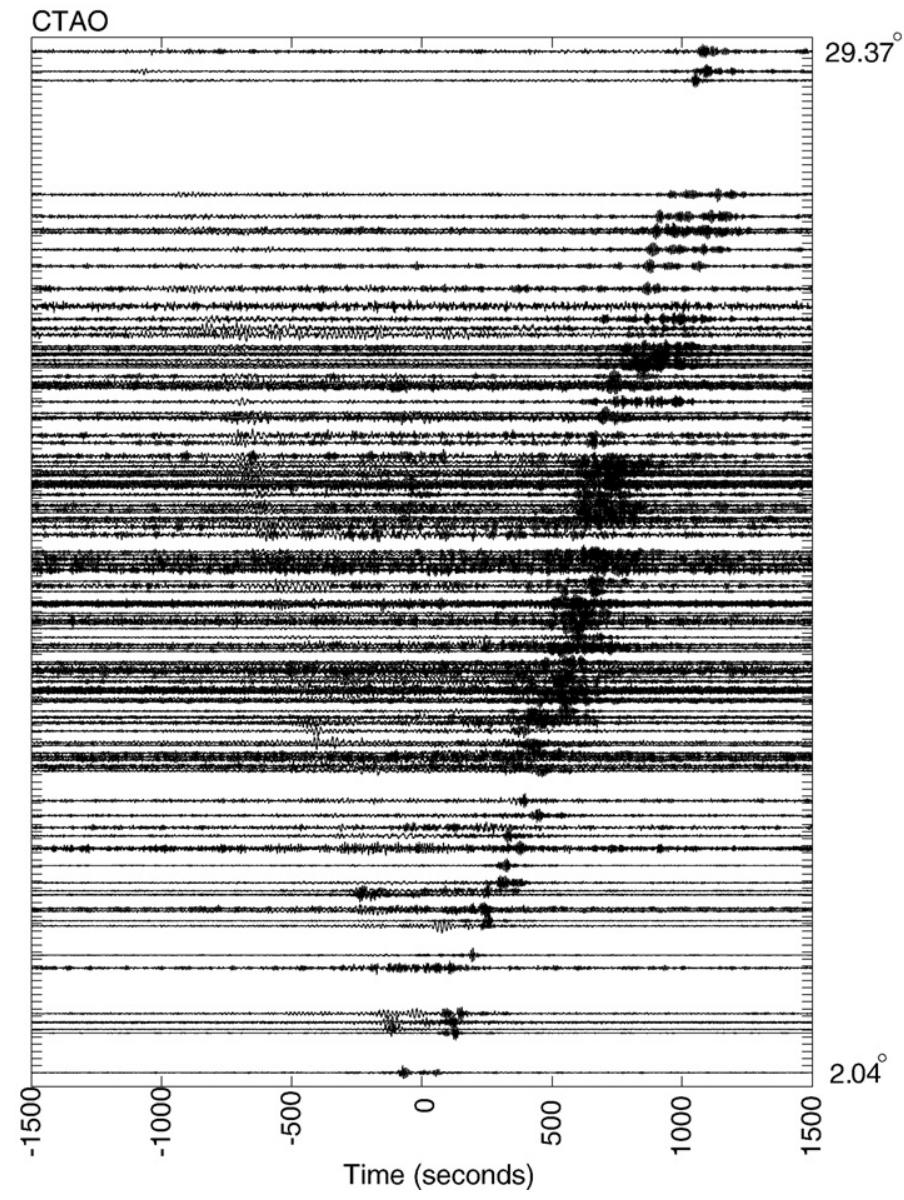

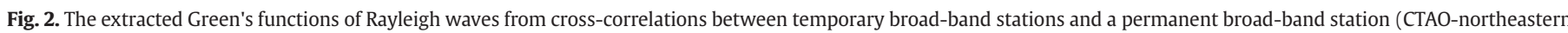
Australia) across Australia with given minimum and maximum interstation distances. Signals are normalised to unity. 
- Average the cross-correlation segments to create a daily estimate.

- Stack all of the averaged cross-correlations for the individual days to improve the signal to noise ratio of the final Green's function.

In this procedure, we do not attempt to exclude seismic events but use long-term averaging to enhance the coherent contributions to the Green's function. In Fig. 2, an example of a record section as a function of distance from the permanent station CTAO in northern Queensland is presented, which is created from the cross-correlation of data from all available temporary stations that operated with the records at CTAO. It has proved possible to obtain high quality rendering of the Rayleigh wave component out to distances of over $3000 \mathrm{~km}$ from CTAO. Some degree of multi-pathing of the Rayleigh waves is visible in the unfiltered records shown in Fig. 2. For uniform spatial excitation of the noise field the positive and negative components of the estimated Green's function would be of equal amplitude. However, the dominant source of noise for CTAO comes from microseisms from the Tasman Sea to the west, rather than the continental area to the east. This asymmetry of noise sources leads to the preponderance of contributions to the positive time response.

\subsection{Group wavespeed from Green's functions}

The frequency content of the extracted Green's function has a strong dependence on the interstation distance. With increasing offset, higher frequencies tend to diminish because of the attenuative properties of the Earth and so Rayleigh waves tend to dominate the extracted Green's function. However, Roux et al. (2005) showed that it is possible to obtain $P$ wave component of the Green's function for closely-spaced receivers with interstation distance less than $11 \mathrm{~km}$. In our analysis, the minimum interstation distance was over $100 \mathrm{~km}$, therefore the Rayleigh wave component of the Green's functions was observed. To find a common frequency range for the group wavespeed measurements from varying interstation distances, we use the period interval from $5 \mathrm{~s}$ to $12.5 \mathrm{~s}$, where most of the extracted Green's functions carry structural information. For longer periods (>12.5 s), the number of measurable Green's functions decreases significantly. In Appendix B, we show the results from a test case with longer period Green's functions. This example shows that with the current data geometry, it is not possible to get a reasonable tomographic image for the Australian continent for these periods.

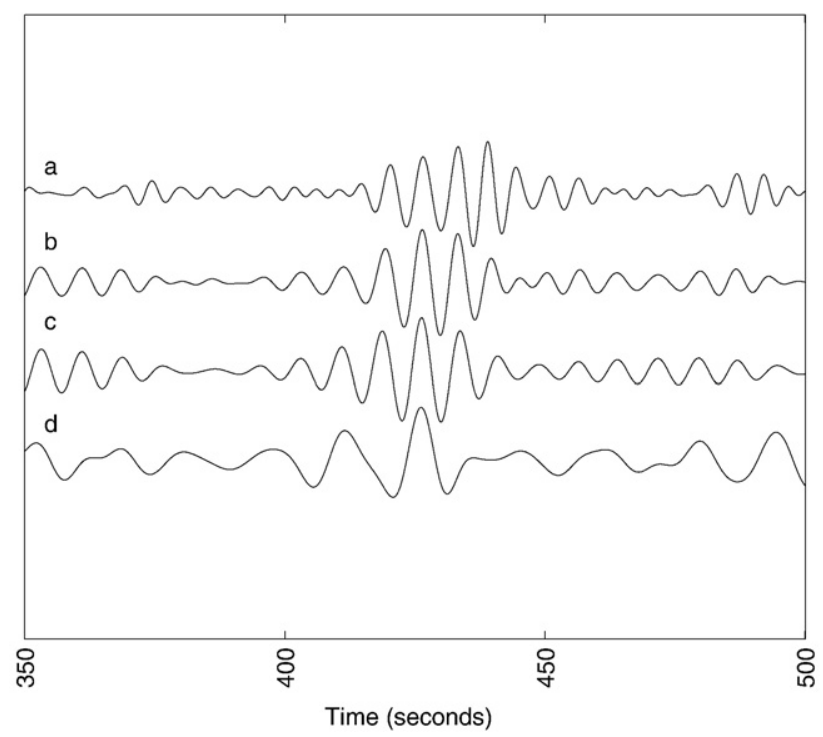

Fig. 3. The effect of bandpass filtering on the Green's function between stations FORT and MG01 with a separation of $11.83^{\circ}$. Centre period a) $\left.\left.5 \mathrm{~s}, \mathrm{~b}\right) 6.6 \mathrm{~s}, \mathrm{c}\right) 8.3 \mathrm{~s}$, and d) $12.5 \mathrm{~s}$.
The group wavespeed measurements are carried out by following the scheme of Dziewonski et al. (1969), where a number of narrow band Gaussian filters are applied to the surface wave and the arrival time for each period is measured by picking the maximum of the envelope of the signal (see Fig. 3 ).

\section{Tomographic inversion}

We apply a nonlinear 2-D tomographic inversion technique for estimating the group wavespeed variations derived from the dispersion measurements from the Green's functions. The propagation paths between the stations are updated at successive iterations so that the influence of the path length can be taken into account.

The fast marching method (FMM) (Sethian and Popovici, 1999; Rawlinson and Sambridge, 2004a,b) is a grid based eikonal solver used in the first step of the inversion for setting the forward problem. The FMM is based on wavefront construction and has certain advantages over conventional ray tracing based methods. FMM offers stable, robust solutions for wave propagation even in highly heterogeneous media, whereas conventional ray tracing methods may fail to converge to the true two-point path, even in the presence of relatively simple structures (Rawlinson and Sambridge, 2004a; de Kool et al., 2006).

The second step of the inversion procedure is based on a local linearisation of the problem about the current model to seek the perturbation of the model parameters to match the group wavespeed measurements. We use the subspace method (Kennett et al., 1988) to reduce the computational cost of this step. The objective function for the tomographic inversion problem can be written as

$\Phi(m)=\left(g(m)-d_{\mathrm{obs}}\right)^{T} W_{\mathrm{d}}^{-1}\left(g(m)-d_{\mathrm{obs}}\right)+\epsilon\left(m-m_{0}\right)^{T} W_{\mathrm{m}}^{-1}\left(m-m_{0}\right)+\eta \mathrm{m}^{T} D^{T} D m$,

where $g(m)$ are the predicted group traveltimes from the model, $d_{\text {obs }}$ are the observed group traveltimes, $W_{\mathrm{d}}$ is the data weighting matrix, $m_{0}$ is the reference model, $W_{\mathrm{m}}$ is the model parameter covariance matrix, $D$ is flatness/smoothness matrix, $\varepsilon$ is the damping parameter, and $\eta$ is the smoothing parameter.

Following Rawlinson and Sambridge (2003) we find the minimum of the objective function with the subspace method, which is an iterative-nonlinear solver. The subspace method works by projecting the quadratic approximation of $\Phi$ onto an $n$-dimensional subspace of the model space. The perturbation is given by

$\delta m=-A\left[A^{T}\left(G^{T} W_{\mathrm{d}}^{-1} G+\epsilon W_{\mathrm{m}}^{-1}+\eta D^{T} D\right) A\right]^{-1} A^{T} \hat{\gamma}$,

where $A=\left[a^{j}\right]$ is the $M \times n$ projection matrix, $G$ is the Fréchet derivatives matrix, $\hat{\gamma}$ is the gradient vector $(\gamma=\partial \Phi / \partial m$ and $\gamma=W$ $\mathrm{m} \hat{\gamma})$. The search directions are given by $a^{j}$ where the first search direction $a^{1}$ corresponds to steepest ascent. We have used a 6dimensional subspace in the inversions presented in this paper.

Once the model perturbation is estimated, we update the current model and then retrace the propagation paths using the FMM scheme. The combination of the FMM for calculation of the forward problem and the subspace method for inversion provides stable and robust tomographic imaging.

\subsection{Resolution and parameter tests}

To investigate the potential resolution of the tomographic results, we have used a synthetic checkerboard test with the actual path distribution. For the 2-D group velocity problem we specify an alternating pattern of low and high velocity perturbations and then try to recover this pattern with the available path coverage. Two sets of tests were conducted for perturbations with horizontal scales of $2^{\circ} \times 2^{\circ}$ and $1^{\circ} \times 1^{\circ}$ with a maximum velocity perturbation of $1 \mathrm{~km} / \mathrm{s}$, with addition of Gaussian noise to each of the paths with a standard deviation of $0.8 \mathrm{~s}$. The inversion was then carried out with the subspace method. 


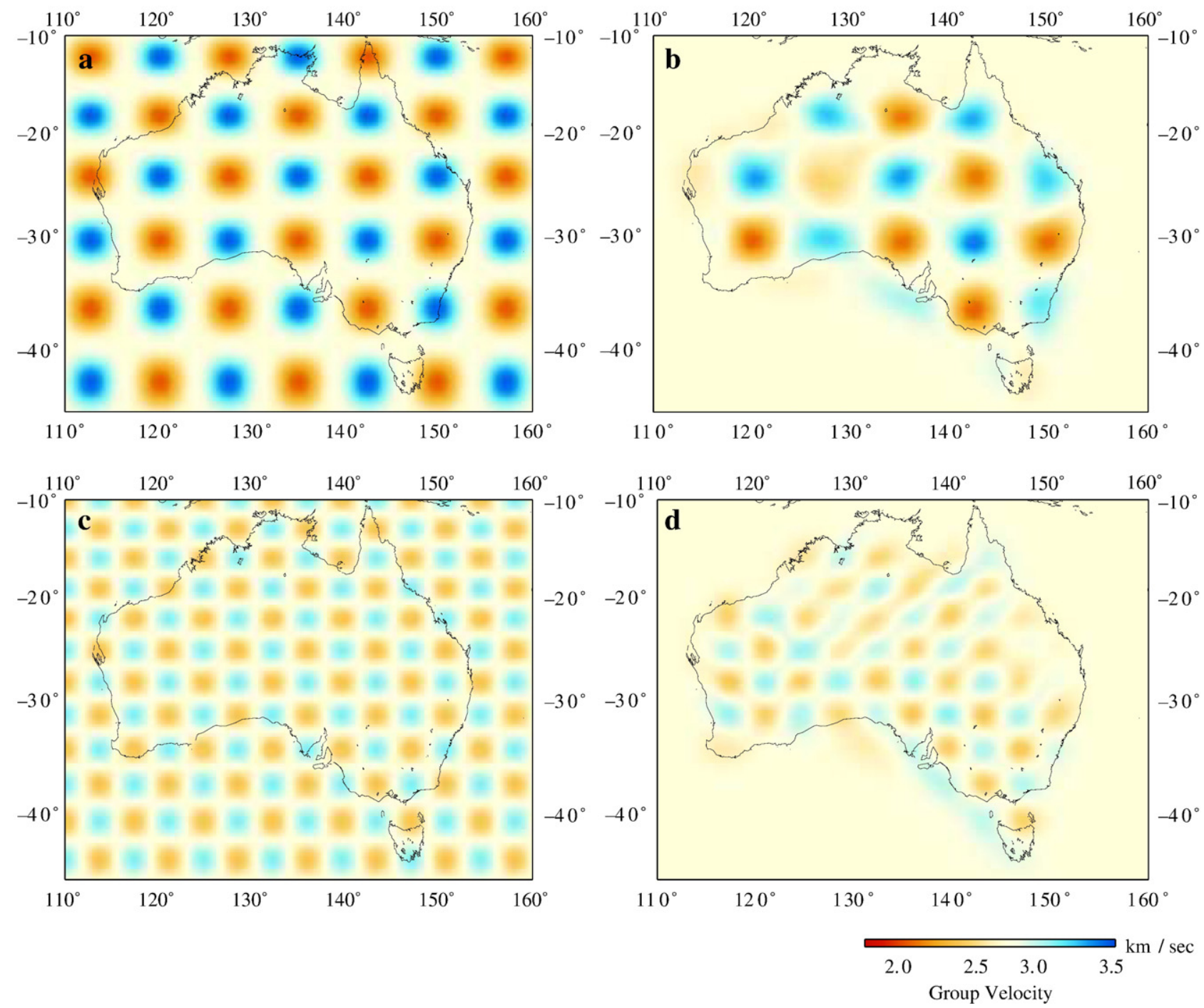

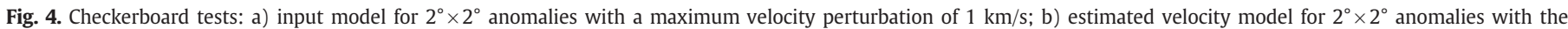

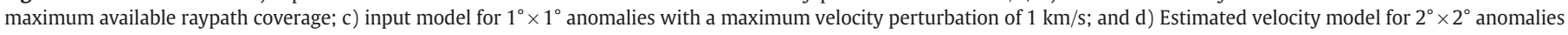
with the maximum available raypath coverage.

Although, checkerboard tests provide useful information for assessing the reliability of the tomographic inversion, some care has to be taken in interpreting the success of the recovery of the synthetic structure as an indicator for the results for the real structure. Lévêque et al. (1993) have shown that a simple checkerboard test only depicts the resolution for a certain class of anomaly, since it is possible to recover small scale structure using particular path coverage that may not able to resolve larger scale anomalies.

From the checkerboard results (Fig. 4), we can infer that the general recovery is good for both of the cell sizes. However, at the edges and in mid-west Australia, we see limited recovery of structure in some patches, and further horizontal smearing is evident due to the gaps in the recorder coverage and the distinct time periods for the different temporary deployments. The smearing effects are most visible for the $1^{\circ} \times 1^{\circ}$ cell size. We employ a $2^{\circ} \times 2^{\circ}$ grid in the inversion to accommodate these effects. Nevertheless, the distributions of available paths from the cross-correlation analysis provide a reasonable imaging of horizontal gradients in group wavespeed through the Australian crust.

\subsection{Tomographic model}

The 2-D maps of the group wavespeed of the Rayleigh waves derived from the tomographic inversion of the group velocity estimates from the ambient noise correlations are displayed in Fig. 5 . The rather large variations in group wavespeed require a fully nonlinear inversion with update of propagation paths. There are substantial deviations from the great circle paths especially around the regions with lowered wavespeed.

The trade-off between the data and satisfying the regularization constraints were explored by inverting with different sets of damping and smoothing values from a range of 0 to 50,000 . Although wide range of parameters was investigated, the final images did not show major differences.

The tomographic images presented in Fig. 5 correspond to different frequency components of the surface wave propagation and so sample the Australian crust at different depths. The synthetic test detailed in the Appendix A (Fig. 7) suggest that the images for periods of $5 \mathrm{~s}$ and $6.6 \mathrm{~s}$ will be dominated by the 2-D structure of the thick sediments of Australian continent, particularly for the regions of lowered group velocities. On the other hand, the images from $8.3 \mathrm{~s}$ to $12.5 \mathrm{~s}$ will largely have the signature of the structure from midcrustal depths (10-20 km). For the relative high frequencies being considered, the features seen will correspond directly to the structure beneath the mapped points.

There is a good spatial correspondence between the features of the group wavespeed anomaly map and aspects of the major geological 

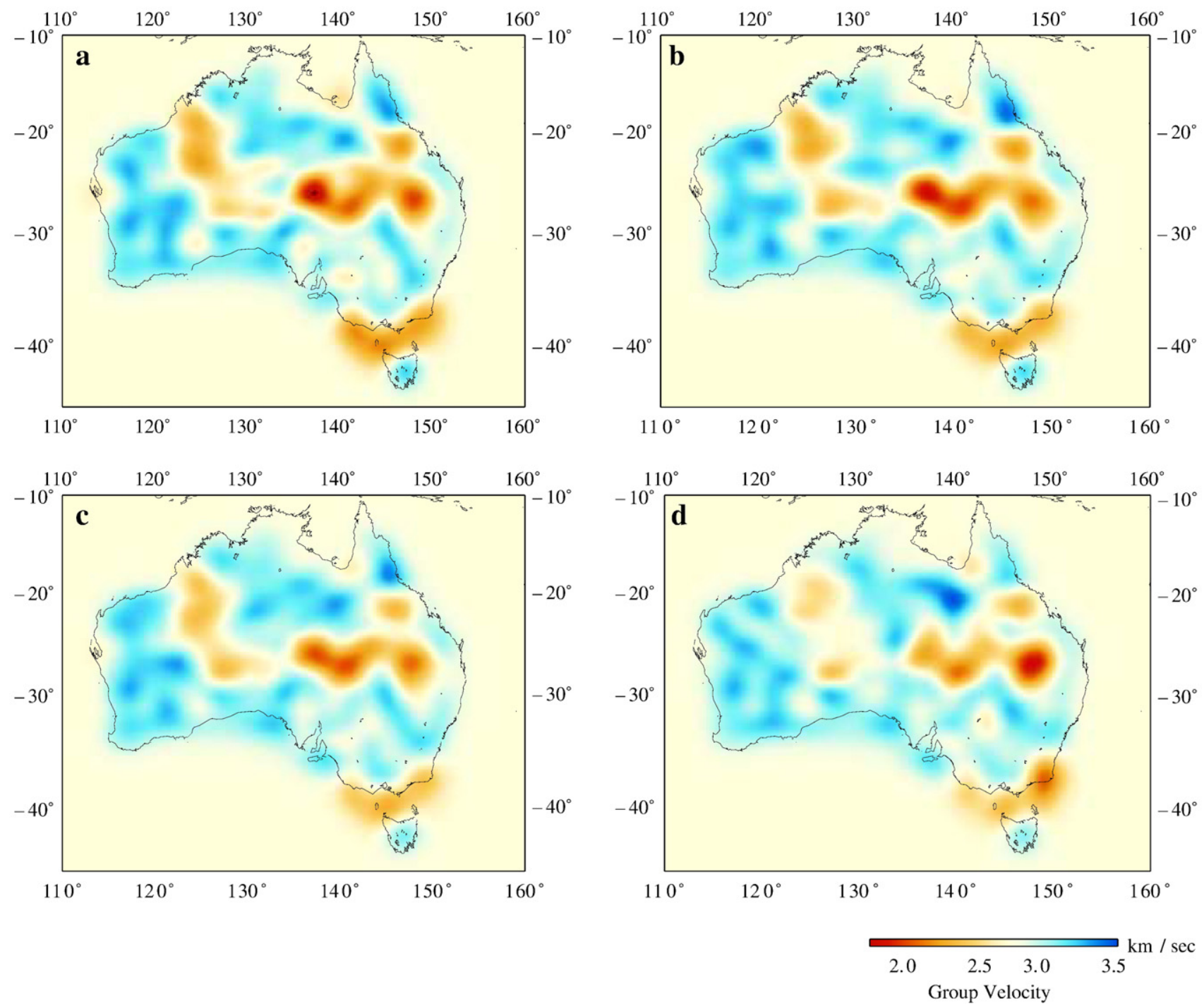

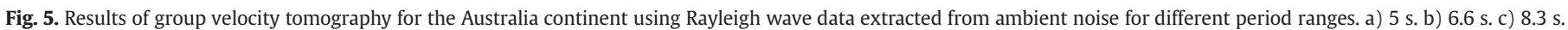
d) $12.5 \mathrm{~s}$.

provinces of Australia shown in Fig. 6a. The estimated group wavespeeds vary from $1.8 \mathrm{~km} / \mathrm{s}$ in the east to $3.6 \mathrm{~km} / \mathrm{s}$ in the west with an average velocity of $3.2 \mathrm{~km} / \mathrm{s}$. The lowered wavespeeds have a strong correlation with the thick sedimentary cover and petroleum deposits.

The images in Fig. 5 have been constructed without any a priori geological input, but reproduce many known features of the surface geology with considerable fidelity. As expected the lowered group velocities for the shortest period ( $5.5 \mathrm{~s}$ ) shown in Fig. 5a correlate very well with the known sedimentary basins and petroleum deposits (see Fig. 1a). In particular the bifurcation of the western lowered group velocities in central Australia corresponds to the wrap of sediments around the Musgrave Block. This feature cannot be reproduced without including path updates in the inversion. The sharp boundary (Fitzroy Trough) between the Canning Basin and the King Leopold belt at the southwestern edge of the Kimberley Block is also very clear as a termination of the high group wavespeeds.

In addition to the prominent zones of lowered group wavespeed we see variability within the zones with the faster group speeds. In the Yilgarn Craton of Western Australia the patterns resemble the variations inferred by Reading et al. (2007) from receiver function analysis, with a link to terrane boundaries. It is interesting to note that the strong contrast in the age of crustal material between central and eastern Australia does not have a direct expression in any of the images in Fig. 5; this point is taken up below. We do see prominent areas of low wavespeed beneath the surface cover including an embayment into central Australia extending as far as the Amadeus Basin.

\section{Discussion}

The group velocities in the period range we have studied are strongly influenced by the presence of sediments and by the physical properties at upper- to midcrustal depths. We have therefore used two different but closely linked approaches to interpret the feature of the tomographic images for different depths.

From the modelling of the Rayleigh wave derivatives in the Appendix A (Fig. 7), the high frequency surface waves are particularly sensitive to near surface structure. The sediments will be thus have the greatest influence on the images at the shortest period, and this is indeed seen. There is a strong correlation of some of the major low velocity anomalies of the images with sediment thickness. In Fig. 6b, a map of sediment thickness for Australia is presented using a $2^{\circ} \times 2^{\circ}$ grid (Laske and Masters, 1997).

For the longer periods, the sampling area is in midcrustal depths $(10-20 \mathrm{~km})$, where seismic velocity is higher. Low group velocity is 

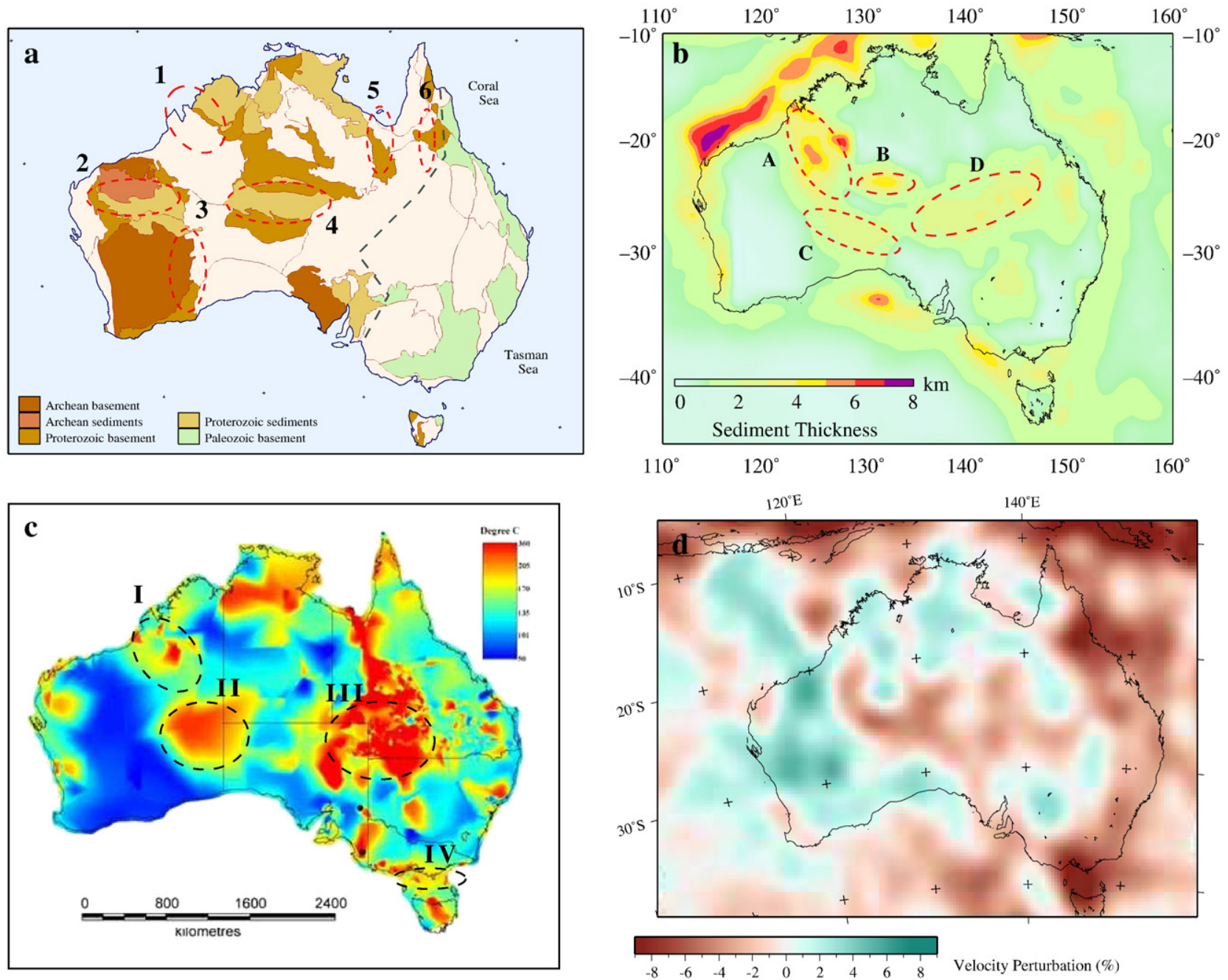

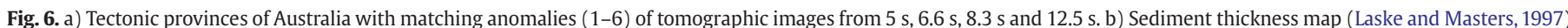

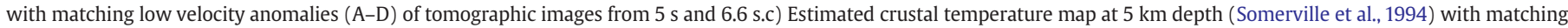

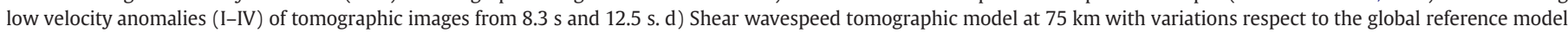
ak135 of Kennett et al. (1995) and Fishwick and Reading (2008).

associated with reduced wavespeeds in this depth interval. Temperature effects have a much strong influence than typical compositional variations; elevated temperatures will markedly reduce seismic velocities (Spencer and Nur, 1976; Duffy and Anderson, 1989; Christensen and Mooney, 1995). In Fig. 6c we show the map of the crustal temperatures at $5 \mathrm{~km}$ depth, estimated from the boreholes (Somerville et al., 1994). Some of the features in the tomographic images of the longer periods (Fig. 5c,d) which do not directly correlate with the surface geology and the surface sediments information can be explained by incorporating the effect of increased temperature on the seismic wavespeeds.

Western Australia is the oldest and most stable part of the continent. The Archaean cratons have the fastest group wavespeed structure, which also complies with the previous findings of surface wave studies e.g., Zielhuis and van der Hilst (1996), Fishwick et al. (2005), Fishwick and Reading, (2008) for greater depths. However,

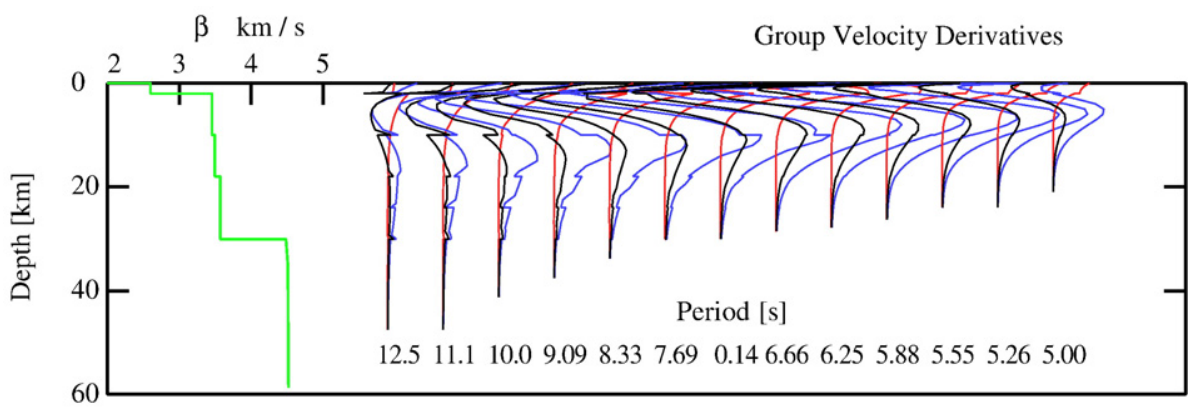

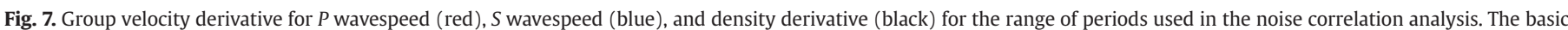
model is for the a cratonic structure with a crustal thickness of $30 \mathrm{~km}$ with a thick surface sedimentary layer (3 km). 
the tomographic images of this study do not show a clear separation between the boundaries of the Pilbara Craton in the north and the Yilgarn Craton in the south, where the extracted group velocities are higher than the other parts of the continent (Figs. 5-6a [2,3] and Fig. 1a). Additional stations have recently been deployed across this transition so that improvements in resolution can be expected in the future. The limited path coverage at the western margin of the continent means that we do not have structural control for this region.

The tomographic images for central Australia display some striking features. Between the Western Australian and the North Australian Craton, a low velocity region with velocities around $2.5 \mathrm{~km} / \mathrm{s}$ indicates the existence of thick sediments. The two branch structure of the low velocity anomaly correlates with location of the Amadeus Basin in the north and Officer Basin in the south (Figs. 5a,b-6a (Claerbout, 1968) [4] and Fig. $6 \mathrm{~b}[\mathrm{~B}, \mathrm{C}])$. The Musgrave Block is located between these two basins and shows a clear signature on the tomographic images. In the north, the location of Kimberley Block is well recovered from east (Figs. 5a,b-6a (Bensen et al., 2007) [1] and Fig. 6b [A]). Although Kimberley Block is covered with ancient sediments with little basement exposed, Graham et al. (1999) suggested the existence of an Archaean lithospheric-mantle keel from the analysis of isotopic data. This idea is supported by the fast wavespeeds from the tomographic images for longer periods. This result is consistent with the high velocity anomaly for this region in the upper part of the mantle lithosphere in the surface wave tomography of Fishwick et al. (2005), Fishwick and Reading (2008) (Fig. 6d).

East of the North Australian Craton, the Mt. Isa Block comprises one of the largest Proterozoic areas in the continent (Betts et al., 2002). This block shows up with a high group wavespeed in the tomographic images (Figs. 5a-6a (Cleary, 1967) [6]), with a rather sharp southern boundary that is frequency dependent. To the east of the Mt. Isa Block, lies the Proterozoic Georgetown Inlier that has also fast group wavespeeds around $3.2 \mathrm{~km} / \mathrm{s}$ (Figs. 5a-6a (Clitheroe et al., 2000) [6]). Simons et al. (1999) concluded that this block was underlain by a rather thin high wavespeed zone in the mantle lithosphere with a pronounced low velocity zone underneath this block. The dip in group wavespeeds between the Mt. Isa and Georgetown Blocks is consistent with the results from a 2007 seismic reflection survey between the two blocks. It would appear that the two Proterozoic blocks are separated by a zone of Palaeozoic material with perhaps a kilometer of surface sediments.

In eastern Australia, considerable interest has been focussed on the Tasman Line, marking the eastern edge of the Precambrian shield areas of central and west Australia. The concept originated with (Hill, 1951), but the limited surface outcrop has meant that various correlations have been used to define different Tasman Line. Direen and Crawford (2003) have compiled various types of geophysical evidence and definitions of Tasman Line. Fishwick et al. (2005), Fishwick and Reading (2008) and Kennett et al. (2004) have presented the shear wave velocity structure for the Australian mantle lithosphere, which shows a significant contrast between the east, and the centre and west of the continent for depths below $75 \mathrm{~km}$. In the tomographic images for the group wavespeed, the shorter periods show multiple short velocity zones with velocities lower than $2.0 \mathrm{~km} / \mathrm{s}$, which also coincide with the sediment thickness map (Figs. 5a,b-6b [D]). However, the orientation of the anomalies does not present a single well defined boundary between Precambrian and Phanerozoic Australia. On the eastern fringe of the continent, there is another low velocity region but we have to be careful in the attribution of this structure, since the ray path distribution is rather limited.

For longer periods, some of the low velocity anomalies show strong correlation with the estimated crustal temperature at depth even though the surface sediments do not extend to these depths (Figs. 5c,d-6c [I-IV]). Several of these zones correspond to petroleum provinces and the heat input is likely to have contributed to hydrocarbon maturation. In eastern central Australia there is a coincidence of sediments and high temperatures beneath (which are being exploited in geothermal exploration).

In the southeast of Australia there is clear zone of reduced group wavespeeds corresponding to the Bass Strait between Tasmania and mainland Australia and its surroundings. This region has multiple small sedimentary basins; with major oil production in the east, where we see signs of possible temperature induced anomalies at the longest period. In Bass Strait itself there is no significant sediment cover but reduced group wavespeeds correlates with a shallow crustal temperature anomaly (Fig. 6c [IV]). At the western end of this zone there are prospective sediments, and also the influence of recent volcanism with the last eruption in southernmost South Australia at 6000 b.p.

\section{Conclusions}

We have achieved the first continent wide tomographic imaging of the Australian crust exploiting cross-correlations of the seismic noise between temporary and permanent stations. Permanent stations have been used as tie-points to link results from the different portable deployments that do not overlap in time.

The tomographic images from the inversion of the group wavespeeds of the ambient-noise Green's functions clearly reveal the major tectonic blocks in the crust. The Archaean cratons in Western Australia have a distinctive signature mark with particularly fast group wavespeeds. The location of the major sedimentary basins is clearly mapped with shorter period surface waves such as Amadeus and Officer Basins in central Australia and the Fitzroy Trough at the

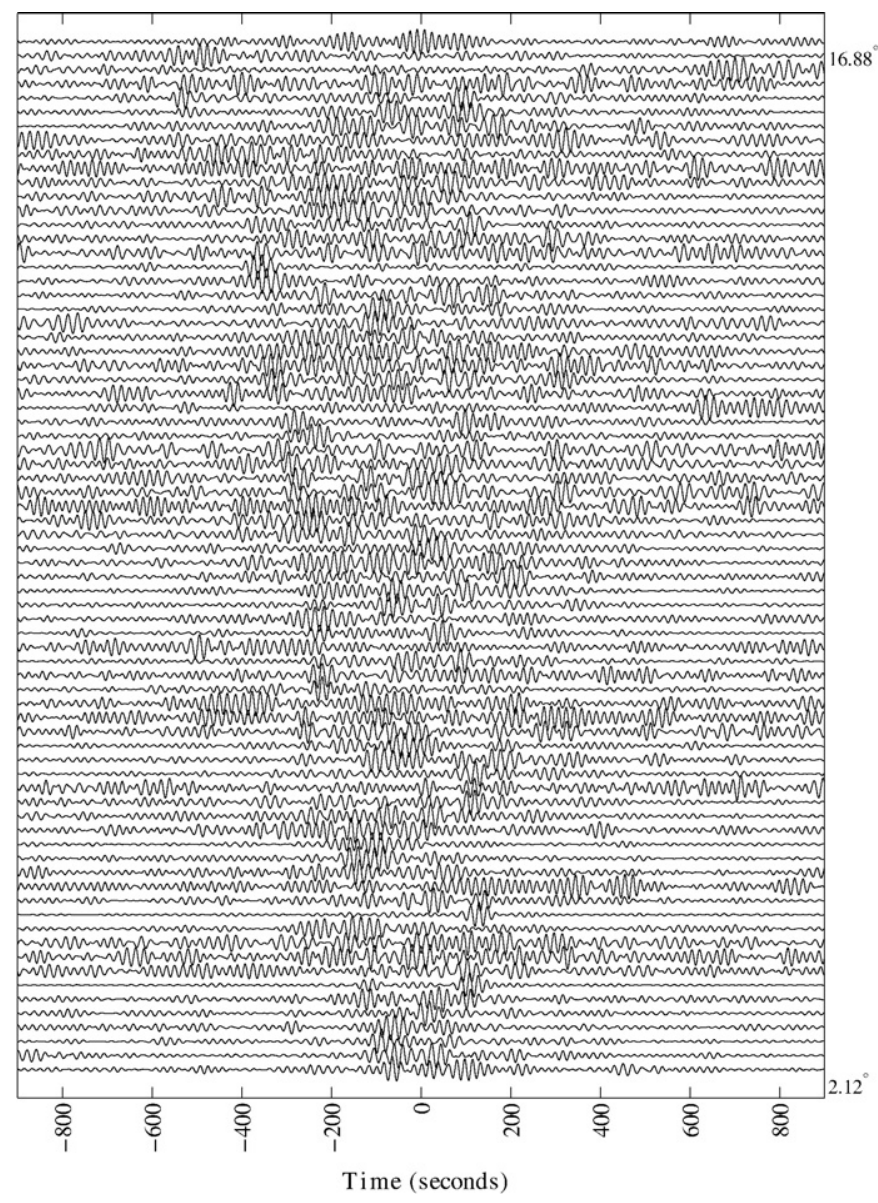

Fig. 8. The constructed Green's functions from Tasmal experiment with spectral whitening. Waveforms are filtered with $0.05 \mathrm{~Hz}$ narrow band filter and normalised to unity. 

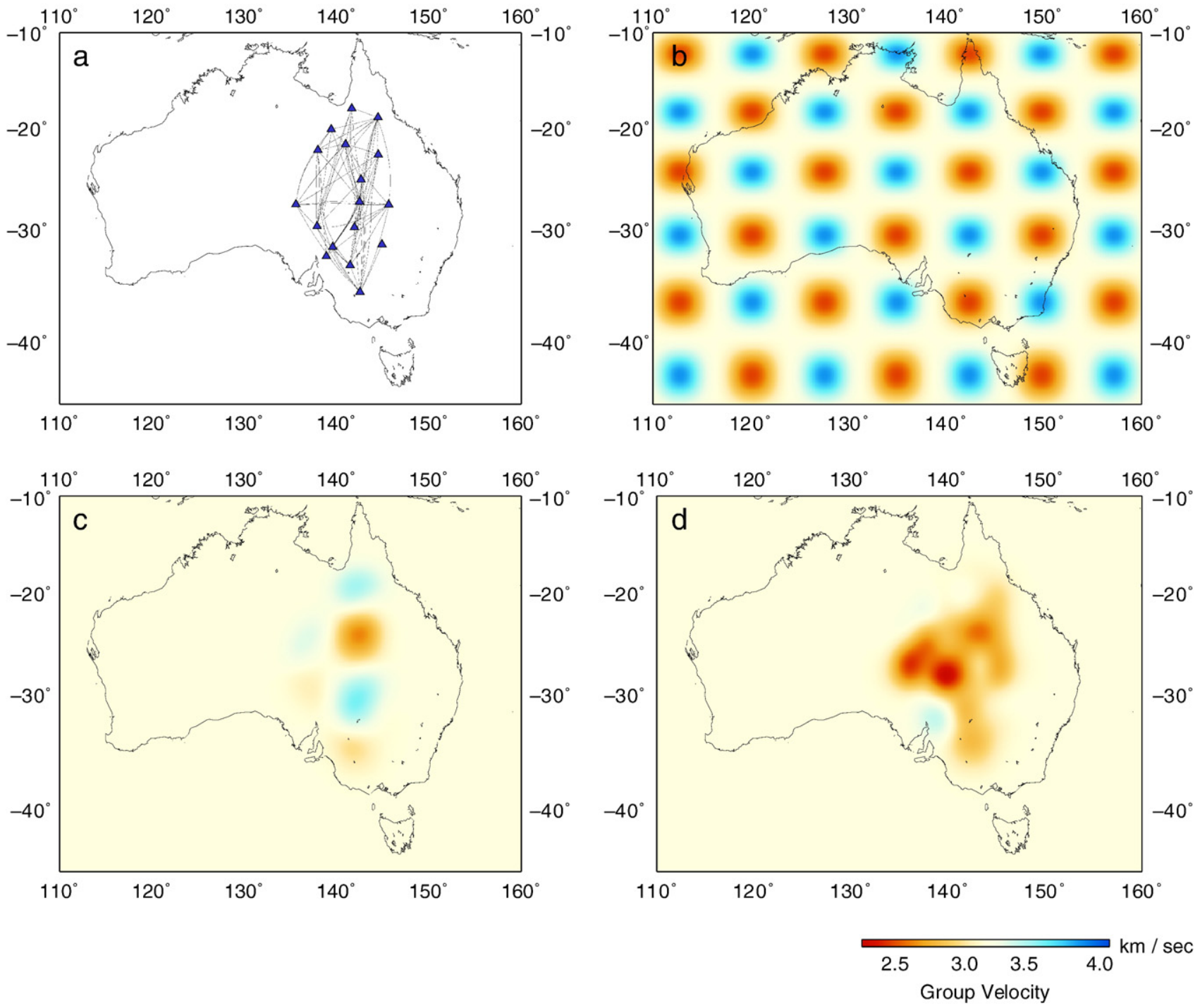

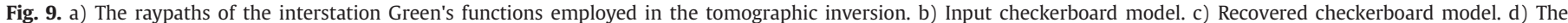
tomographic image from the measured Green's functions at $0.05 \mathrm{~Hz}$.

edge of Kimberley. The transition to structural blocks with large velocity contrasts is accurately recovered as in the Kimberley Block.

For longer periods, some of the low group velocity anomalies show strong correlation with the estimated crustal temperatures at depth, even though the sediments do not extend to these depths. This suggests the significance of the elevated crustal temperatures for producing slower seismic wave propagation.

The nature of the wavespeed anomalies in the region of the transition from Precambrian to Phanerozoic Australia (Tasman Line) do not suggest a single well defined boundary in contrast to the tomographic images for the mantle lithosphere (150-200 km) derived from surface wave tomography studies (Fishwick et al., 2005; Fishwick and Reading, 2008).

\section{Acknowledgement}

E. Saygin was supported by an International Postgraduate Research Scholarship at the Australian National University and ARC (Australian Research Council) Discovery Grant DP0342618. The data from the permanent stations was acquired from the IRIS data repository. We thank the technical, research and field staff from RSES for their efforts during all of the temporary deployments and in subsequent data handling. The maps presented in this paper have been prepared with GMT software (Wessel and Smith, 1991).

\section{Appendix A: Depth sensitivity}

It is important to interpret the depth ranges sampled by the different periods of the surface waves. We employ a velocity model with a thick sedimentary layer $(\approx 3 \mathrm{~km})$ which occurs over much of the Australian continent in addition to the surface regolith. In Fig. 7, the derivatives of the group velocities are shown for the $P, S$ and density for the period ranges employed in the tomographic inversion. For shorter periods, it is clear from the amplitude of the shear wavespeed curve that the surface waves will sample more of the thick sedimentary layer. But with increasing periods, the sampling area will be confined to midcrustal depths of $10-20 \mathrm{~km}$.

\section{Appendix B: Longer period Green's functions}

We perform a test case with the data from Tasmal experiment to show the reason that why this study was not extended to the longer periods of Green's functions. The Tasmal experiment ran between 2003 and 2005 with simultaneously operated 20 broad-band stations in central and eastern Australia (see Fig. 9a) and until now it has been the biggest temporary deployment carried out in Australia. The design of this experiment was done in a way that the geophysical techniques would image the possible transition of Phanerozoic Australia to Precambrian Australia. 
In order to achieve a broader frequency response, we have computed the Green's functions with a water-level type deconvolution (Helmberger and Wiggins, 1971). This deconvolution has a waterlevel parameter $(c)$ which will act as spectral whitening operator similar to the given one in Bensen et al. (2007).

$\Phi(\omega)=\frac{v\left(x_{\mathrm{A}}, \omega\right) v^{*}\left(x_{\mathrm{B}}, \omega\right)}{\varphi_{\mathrm{sS}}(\boldsymbol{\omega})}$,

where

$\varphi_{\mathrm{ss}}(\boldsymbol{\omega})=\max \left[v\left(x_{\mathrm{B}}, \omega\right) v^{*}\left(x_{\mathrm{B}}, \omega\right), C \max \left[v\left(x_{\mathrm{B}}, \omega\right) v^{*}\left(x_{\mathrm{B}}, \boldsymbol{\omega}\right)\right]\right]$,

$v\left(x_{\mathrm{A}}, \omega\right)$ and $v\left(x_{\mathrm{B}}, \omega\right)$ are the Fourier transforms of the recorded seismic velocity field at the stations $\mathrm{A}$ and $\mathrm{B}$, and * denotes the complex conjugation.

The phase response is then the same as for the cross correlation, but the dependence on the amplitude spectrum of the noise is reduced. We use 0.1 for the water-level parameter and then we filtered Green's functions $(\Phi(t))$ with a narrow-band filter centred at $0.05 \mathrm{~Hz}$. At the end of careful hand-picking, less than half of the (74) extracted Green's functions showed consistent arrivals (see Fig. 8). We then employed a $2^{\circ} \times 2^{\circ}$ tomographic inversion with these measurements. The results are given in Fig. 9d. Interestingly, a low velocity anomaly exists in the centre of the image, which suggests that the proposed elevated temperatures affect the wave propagation at larger depths where the sediments do not extend. However, one should be cautious about the integrity of this model, where resolution is crude due to the limited number of group velocity measurements. The accompanying checkerboard test shows extensive smearing in the eastern part of the network.

If we extend this analysis to the current data, the number of measurable Green's functions will be significantly less than 2000 due to the current geometry of the dataset; independent deployments and limited number of permanent stations. In this case, it would be questionable to recover a reasonable tomographic image for larger periods.

\section{References}

Bensen, G.D., Ritzwoller, M.H., Barmin, M.P., Levshin, A.L., Lin, F., Moschetti, M.P Shapiro, N.M., Yang, Y., 2007. Processing seismic ambient noise data to obtain reliable broad-band surface wave dispersion measurements. Geophys. J. Int. 169, 1239-1260. doi:10.1111/j.1365-246X.2007.03374.x.

Betts, P.G., Giles, D., Lister, G.S., Frick, L.R., 2002. Evolution of the Australian lithosphere Aust. J. Earth Sci. 49, 661-695.

Christensen, N.I., Mooney, W.D. 1995. Seismic velocity structure and composition of the continental crust: a global view. J. Geophys. Res. 100, 9761-9788.

Claerbout, J.F., 1968. Synthesis of a layered medium from its acoustic transmission response. Geophysics 33 (2), 264-269.

Cleary, J., 1967. $P$ times to Australian stations from nuclear explosions. Bull. Seism. Soc Am. 57, 773-781.

Clitheroe, G., Gudmundsson, O., Kennett, B.L.N., 2000. The crustal thickness of Australia. J. Geophys. Res. 105, 13,697-13,713.

Collins, C.D.N., Drummond, B.J., Nicoll, M.G., 2003. Crustal thickness patterns in the Australian continent. In: Hillis, R.R., Muller, R.D. (Eds.), The Evolution and Dynamic of the Australian Plate. Geological Societies of Australia and America, pp. 121-128.

de Kool, M., Rawlinson, N., Sambridge, M., 2006. A practical grid based method fo tracking multiple refraction and reflection phases in 3D heterogeneous media. Geophys. J. Int. 167, 253-270.

Debayle, E., Kennett, B.L.N., 2003. Surface wave studies of the Australasian region. In: Hillis, R.R., Muller, R.D. (Eds.), The Evolution and Dynamics of the Australian Plate. Geological Societies of Australia and America, pp. 25-40.

Direen, N.G., Crawford, A.J., 2003. The Tasman Line: where is it, what is it, and is it Australia's Rodinian breakup boundary? Aust. J. Earth Sci. 50, 491-502.

Duffy, T.S., Anderson, D.L., 1989. Seismic velocities in mantle minerals and the mineralogy of the upper mantle. J. Geophys. Res. 94 (B2), 1895-1912.

Duvall, T.L., Jefferies, S.M., Harvey, J.W., Pomerantz, M.A., 1993. Time-distance helioseismology. Nature 362, 430-432.

Dziewonski, A.S., Bloch, S., Landisman, M., 1969. A technique for the analysis of transient seismic signals. Bull. Seismol. Soc. Am. 59, 427-444.

Fishwick, S., Reading, A.M., 2008. Anomalous lithosphere beneath the Proterozoic of western and central Australia: a record of continental collision and intraplate deformation? Precambrian Res. 166, 111-121. doi:10.1016/j.precamres.2007.04.026.

Fishwick, S., Kennett, B.L.N., Reading, A.M., 2005. Contrasts in lithospheric structure within the Australian Craton. Earth Planet. Sci. Lett. 231, 163-176.
Graham, S, Lambert, D.D., Shee, S.R Smith, C.B., Reeves, S, 1999. Re-Os isotopic evidence for Archaean lithospheric mantle beneath the Kimberley Block, Western Australia. Geology 27, 431-434.

Gudmundsson, Ó., Khan, A., Voss, P., 2007. Rayleigh-wave group-velocity of the Icelandic crust from correlation of ambient seismic noise. Geophys. Res. Lett. 34 L14314. doi:10.1029/2007GL030215.

Helmberger, D., Wiggins, R., 1971. Upper mantle structure of midwestern United States. J. Geophys. Res. 76, 3229-3245.

Hill, D., 1951. Geology. In: Mack, G. (Ed.), Handbook of Queensland. Australian Association for the Advancement of Science, Brisbane, pp. 13-24.

Kang, T.-S., Shin, J.S., 2006. Surface-wave tomography from ambient seismic noise of accelerograph networks in southern Korea. Geophys. Res, Lett. 33, L17303. doi:10.1029/2006GL027044

Kennett, B.L.N., Sambridge, M., Williamson, P.R., 1988. Subspace methods for large scale inverse problems involving multiple parameter classes. Geophys. J. Int. 94, 237-247.

Kennett, B.L.N., 2003. Seismic structure in the mantle beneath Australia. In: Hillis, R.R., Muller, R.D. (Eds.), The Evolution and Dynamics of the Australian Plate. Geological Societies of Australia and America, pp. 7-23.

Kennett, B.L.N., Engdahl, E.R., Buland, R., 1995. Constraints on seismic velocities in the Earth from travel times. Geophys. J. Int. 122, 108-124.

Kennett, B.L.N., Fishwick, S., Reading, A.M., Rawlinson, N., 2004. Contrasts in mantle structure beneath Australia: relation to Tasman Lines? Aust. J. Earth Sci. 51, 563-569.

Laske, G., Masters, G., 1997. A global digital map of sediment thickness. EOS Trans. AGU 78, F483.

Lee, Y.W., 1960. Statistical Theory of Communication. Wiley, New York.

Lévêque, J.J., Rivera, L., Wittlinger, G., 1993. On the use of the checker-board test to assess the resolution of tomographic inversions. Geophys. J. Int. 115, 313-318.

Lin, F., Moschetti, M.P., Ritzwoller, M.H., 2008. Surface wave tomography of the western United States from ambient seismic noise: Rayleigh and Love wave phase velocity maps. Geophys. J. Int. doi:10.1111/j1365-246X.2008.03720.x.

Moschetti, M.P., Ritzwoller, M.H., Shapiro, N.M., 2007. Surface wave tomography of the western United States from ambient seismic noise: Rayleigh wave group velocity maps. Geochem., Geophys., Geosys. 8, Q08010. doi:10.1029/2007GC001655.

Rawlinson, N., Sambridge, M., 2003. Seismic traveltime tomography of the crust and lithosphere. Adv. Geophys. 46, 81-198.

Rawlinson, N., Sambridge, M., 2004a. Wavefront evolution in strongly heterogeneous layered media using the fast marching method. Geophys. J. Int. 156, 631-647.

Rawlinson, N., Sambridge, M., 2004b. Multiple reflection and transmission phases in complex layered media using a multistage fast marching method. Geophysics 69, 1338-1350.

Reading, A.M., Kennett, B.L.N., 2003. Lithospheric structure of the Pilbara Craton, Capricorn Orogen and northern Yilgarn Craton, Western Australia, from teleseismic receiver functions. Aust. J. Earth Sci. 50, 439-445.

Reading, A.M., Kennett, B.L.N., Dentith, M.C., 2003. Seismic structure of the Yilgarn Craton, Western Australia. Aust. J. Earth Sci. 50, 427-438.

Reading, A.M., Kennett, B.L.N., Goleby, B., 2007. New constraints on the seismic structure of West Australia: evidence for terrane stabilisation prior to the assembly of an ancient continent? Geology 35 (4), 379-382. doi:10.1130/G23341A.1.

Roux, P., Sabra, K.G., Gerstoft, P., Kuperman, W.A., Fehler, M.C., 2005. P-waves from crosscorrelation of seismic noise. Geophys. Res. Lett. 32, L19303. doi:10.1029/2005GL023803.

Sabra, K.G. Gerstoft, P. Roux, P. Kuperman, W.A., Fehler, M.C., 2005. Surface wave tomography from microseisms in Southern California. Geophys. Res. Lett. 32, L14311. doi: 10.1029/2005GL023155.

Sethian, J.A., Popovici, A.M., 1999. 3-D traveltime computation using the fast marching method. Geophysics 64, 516-523.

Shapiro, N.M., Campillo, M., 2004. Emergence of broadband Rayleigh waves from correlations of the ambient seismic noise. Geophys. Res. Lett. 31. doi:10.1029/2004GL019491.

Shapiro, N.M., Campillo, M., Stehly, L., Ritzwoller, M.H., 2005. High resolution surface wave tomography from ambient seismic noise. Science 307, 1615-1618. doi:10.1126/science.1108339.

Simons, F.J., Zielhuis, A., van der Hilst, R.D., 1999. The deep structure of the Australian continent from surface wave tomography. Lithos 48, 17-43.

Snieder, R., 2004. Extracting Green's function from the correlation of coda waves: a derivation based on stationary phase. Phys. Rev. E 69. doi:10.1103/ PhysRevE.69.046610.

Somerville, M., Wyborn, D., Chopra, P.N., Rahman, S.S., Estrella, D., van der Meulen, T., 1994. Hot Dry Rocks Feasibility Study, Australian Energy Research and Development Corporation Report 94/243, p. 133.

Spencer Jr, J.W., Nur, A.M., 1976. The effects of pressure, temperature, and pore water on velocities in westerly granite. J. Geophys. Res. 81 (5), 899-904.

Thomas, L., 1969. Rayleigh wave dispersion in Australia. Bull. Seismol. Soc. Am. 59, $167-182$

Villaseñor, A., Yang, Y., Ritzwoller, M.H., Gallart, J., 2007. Ambient noise surface wave tomography of the Iberian Peninsula: implications for shallow seismic structure. Geophys. Res. Lett. 34, L11304. doi:10.1029/2007GL030164.

Yao, H., van der Hilst, R.D., de Hoop, M.V., 2006. Surface-wave array tomography in SE Tibet from ambient seismic noise and two-station analysis - I. Phase velocity maps. Geophys. J. Int. 166, 732-744.

Yoshizawa, K., Kennett, B.L.N., 2004. Multimode surface wave tomography for the Australian region using a three-stage approach incorporating finite frequency effects. J. Geophys. Res. 109, B02310. doi:10.1029/2002JB002254

Weaver, R.L., Lobkis, O.I., 2001. Ultrasonics without a Source: thermal fluctuation correlations at $\mathrm{MHz}$ frequencies. Phys. Rev. Lett. 87. doi:10.1103/PhysRevLett.87.134301.

Wessel, P., Smith, W.H.F., 1991. Free software helps map and display data. EOS Trans. AGU 72, 441.

Zielhuis, A., van der Hilst, R., 1996. Upper mantle shear velocity beneath eastern Australia from inversion of waveforms from Skippy portable arrays. Geophys. J. Int 127, 1-16. 